\title{
Post-Hemorrhagic Hydrocephalus
}

National Cancer Institute

\section{Source}

National Cancer Institute. Post-Hemorrhagic Hydrocephalus. NCI Thesaurus. Code C116383.

An abnormal accumulation of cerebrospinal fluid within the ventricles of the brain that occurs as a later sequela of an intraventricular or subarachnoid hemorrhage. 